\title{
Cigarrinha-do-milho e o complexo de enfezamentos em Santa Catarina: panorama, patossistema e estratégias de manejo
}

\author{
Leandro do Prado Ribeiro ${ }^{1}$ e Maria Cristina Canale ${ }^{2}$
}

Resumo - Surtos populacionais de cigarrinha-do-milho (Dalbulus maidis), inseto-vetor dos patógenos (molicutes e vírus) associados ao complexo de enfezamentos, ocorreram na safra 2020/2021 em Santa Catarina, com impacto significativo na produção e na produtividade do milho. Assim, neste informativo são discutidos o panorama do problema no Estado, os principais aspectos etiológicos e bioecológicos dos agentes bióticos envolvidos neste patossistema e as principais estratégias de manejo recomendadas para mitigar o seu impacto nas lavouras de milho nas próximas safras.

Termos para indexação: Dalbulus maidis; Enfezamento-vermelho; Enfezamento-pálido; Virose-da-risca; Transmissão de fitopatógenos por insetos.

\section{Corn leafhopper and corn stunt disease complex in Santa Catarina: overview, pathosystem and management strategies}

\begin{abstract}
Population outbreaks of corn leafhopper (Dalbulus maidis), the insect vector of microorganisms associated with corn stunting, occurred in the 2020/2021 crop year in Santa Catarina State, Brazil, with a significant impact on corn production and productivity. Thus, both an overview of this problem in this State and etiological and bioecological aspects of biotic agents involved in this pathosystem were discussed, as well as the main management strategies recommended to mitigate its impact on corn crops in the next harvests.
\end{abstract}

Index terms: Dalbulus maidis; Maize bushy stunt; Corn stunt; Maize rayado fino disease; Transmission of phytopathogens by insects.

\section{O panorama do problema em Santa Catarina}

A cigarrinha-do-milho, Dalbulus maidis (DeLong \& Wolcott, 1923) (Hemiptera: Cicadellidae), tornou-se uma pragachave do milho no Brasil, especialmente a partir da safra 2014/2015 nas regiões Sudeste e Centro-Oeste (GALVÃO et al., 2019). No entanto, acreditava-se que tal inseto-praga não incidiria em altas populações no sul do Brasil em virtude da ocorrência de inverno com geadas em frequências e intensidades suficientes para eliminar o milho guaxo ou tiguera, principal hospedeiro para sobrevivência e multiplicação de $D$. maidis na entressafra. Mas na safra 2020/2021 foram observados expressivos surtos populacionais dessa espécie-praga em Santa Catarina, impactando significativamente a produção e a produtividade desse cereal. Constatou-se, ainda, uma predo- minância de populações de cigarrinhas infectivas através de testes moleculares (dados não publicados) no início da referida safra no Estado, o que colocou o setor produtivo em alerta.

Os danos ocasionados por esse inseto em decorrência de sua alimentação (sucção de seiva e injeção de toxinas) somente são significativos em altas infestações, sendo o principal impacto decorrente da transmissão de microrganismos patogênicos às plantas, tais como bactérias da classe dos molicutes e vírus causadores de doenças do complexo do enfezamento (Figura 1B, C e D). Em genótipos suscetíveis, a incidência das doenças do complexo de enfezamentos pode reduzir a produtividade do milho em mais de $90 \%$ (TOFFANELLI \& BEDENDO, 2002).

O impacto desse vetor e do complexo de enfezamentos foi verificado em todas as regiões de cultivo de milho em Santa Catarina, com prejuízos variáveis de acordo com a suscetibilidade do híbrido semeado, as condições ambientais e a pressão populacional do insetovetor. As regiões mais afetadas foram as do Extremo-Oeste, Oeste, Meio-Oeste, Planalto Norte e Planalto Serrano, sendo a redução da produção causada por esse problema difícil de ser mensurada em virtude da ocorrência concomitante de estiagem e de outros problemas fitossanitários observados simultaneamente (p. ex.: podridões do colmo e espiga e trips).

\section{Etiologia e sintomatologia: decifrando as confusões no diagnóstico}

A cigarrinha-do-milho transmite para as plantas de milho, de forma persistente propagativa, os agentes causais do enfezamento-vermelho (fitoplasma), do enfezamento-pálido (espiroplasma)

${ }^{2}$ Eng.-agr., Dra. em Fitopatologia, Epagri/Cepaf. E-mail: cristinacanale@epagri.sc.gov.br. 
e da virose-da-risca (Marafivirus). Para isso, a cigarrinha adquire os patógenos quando se alimenta de plantas infectadas, transmitindo esses patógenos às plantas sadias (GALVÃO et al., 2019).

Os sintomas decorrentes dos enfezamentos ocasionados pelos molicutes (fitoplasma e espiroplasma) incluem a redução do porte das plantas (redução de entrenós) e da área foliar, multiespigamento, redução da altura de inserção da espiga (Figura 1B e C) e má-formação de espigas e grãos, que afeta diretamente a produtividade da cultura (VILANOVA, 2021). Os sintomas de enfezamento-vermelho incluem o avermelhamento a partir das margens e do ápice das folhas seguido de seca (Figura 1B), enquanto o enfezamento-pálido apresenta estrias cloróticas localizadas, principalmente, na base das folhas (Figura 1C). Os sintomas da virose-da-risca, por sua vez, se caracterizam por lesões na forma de pequenos pontos cloróticos alinhados (Figura 1D), acompanhados de menor desenvolvimento e porte da planta (WORDELL FILHO et al., 2016). Todavia, a expressão de tais sintomas é variável de acordo com o genótipo do milho, podendo tais doenças ocorrer associadamente como infecções múltiplas (GALVÃO et al., 2019).

Há relatos de que a planta altamente suscetivel a enfezamentos, associada à época de infecção e a condições ambientais favoráveis, pode enfraquecer e tombar em condições de campo, em decorrência da má distribuição de nutrientes na planta infectada e do enfraquecimento do colmo (JUNQUEIRA et al., 2004). Isso tornaria a planta predisposta a podridões ocasionadas por fungos oportunistas de solo, algo ainda a ser elucidado em futuros estudos. Entretanto, uma correta diagnose dos enfezamentos por meio do reconhecimento dos sintomas é essencial para que eles não sejam confundidos com outros problemas fitossanitários, tais como podridões fúngicas e ataques de outros insetos, tais como trips, especialmente Frankliniella williansi Hood, 1915 (Thysanoptera: Tripdae) (Figura 1E) ou

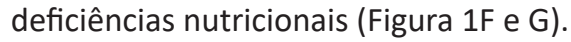

No caso de podridões de colmo e espiga, em geral é possível constatar crescimento fúngico com aspecto de mofo esbranquiçado ou róseo nas espigas, e os colmos podem apresentar desintegração de tecido e coloração parda, rósea e escurecida, dependendo do fungo causador. Os danos ocasionados por trips, que se alimentam da seiva extravasada a partir da raspagem do tecido das folhas pelo inseto, se manifestam com o aparecimento de manchas alongadas de cor esbranquiçada e de contornos irregulares (Figura $1 \mathrm{E}$ ), que pode tornar a folha quebradiça. A deficiência nutricional de potássio (Figura 1F), que pode ser confundida com enfezamentovermelho por causa da coloração típica, pode ser diferenciada pelo tom predominantemente purpúreo em decorrência da falta do nutriente, enquanto a deficiência de manganês, que provoca uma clorose sem uma delimitação clara ao longo de todo o limbo foliar (Figura $1 G)$ entre as nervuras, se confunde com a clorose ocasionada pelo enfezamentopálido, que se caracteriza por se iniciar na base da folha e com delimitação mais evidente.

\section{Aspectos bioecológicos do inseto-vetor, método de amostragem e período crítico}

A presença de adultos da cigarrinhado-milho, $D$. maidis, pode ser verificada visualmente pela inspeção do "cartucho" das plantas (Figura 1A). Para isso, recomenda-se a inspeção de 100 plantas de um talhão por meio de caminhamento em zigue-zague, dando especial atenção àquelas situadas nas bordas da lavoura ou nas proximidades de matas e de cultivos de hospedeiros alternativos [p. ex.: pastagens de gramíneas (Poaceae)]. Armadilhas adesivas amarelas também poderão ser alternativamente utilizadas, especialmente dispostas nas bordas da lavoura.

Adultos de $D$. maidis medem de 3,7 a 4,3mm, têm coloração branco-palha e possuem as asas semitransparentes (Figura 1A). Além disso, na parte frontal (ápice) da cabeça, apresentam duas máculas arredondadas de cor preta, aspecto morfológico que facilita o seu reconhecimento e distinção das demais espécies de cigarrinhas incidentes na cultura (44 espécies descritas de Cica- dellidae e Delphacidae). A longevidade das cigarrinhas adultas é de cerca de dois meses, período em que cada fêmea oviposita até 600 ovos (WAQUIL et al., 1999). A postura é endofítica, ou seja, embaixo da epiderme do limbo foliar. Ocorrem até 5 estádios ninfais, e as ninfas se alojam majoritariamente na parte inferior da folha (face abaxial), são amareladas e completam a fase ninfal em 25 a 30 dias, sendo este período variável de acordo com a temperatura (WAQUIL et al., 1999).

Apesar de utilizar outras espécies de plantas como abrigo na entressafra, $D$. maidis somente se reproduz no milho, no teosinto e em espécies do gênero Tripsacum. Oliveira et al. (2020) verificaram a presença de D. maidis em 17 espécies de plantas (93,8\% Poaceae) na entressafra (agosto-setembro) em Planaltina, DF. Contudo, a longevidade de adultos em hospedeiros alternativos é significativamente reduzida. Cabe ressaltar, no entanto, que estudos demonstraram o alto potencial de migração e dispersão de D. maidis (TAYLOR et al., 1993), geralmente de $30 \mathrm{~km}$ em voos ativos ( $3 \mathrm{~h}$ de duração) e distâncias ainda maiores $(500-1.000 \mathrm{~km}$ ) em voos passivos favorecidos por correntes de vento. A contribuição de populações residentes, oriundas da sobrevivência do milho voluntário (tiguera), e de populações migrantes no estabelecimento da praga no início da safra no Estado ainda é algo desconhecido. Contudo, a eliminação de tigueras é importante para diminuir a população de $D$. maidis na região no período de entressafra (COTA et al., 2021).

Os danos decorrentes do complexo de enfezamentos são maiores quando a infecção dos patógenos acontece em plantas que se encontram nas fases iniciais de desenvolvimento (VILANOVA, 2021). Assim, o período crítico compreende da emergência (VE) até 30-40 dias após (V8), sendo o período de VEV5 ("período supercrítico") aquele que requer maior atenção na adoção de medidas de manejo (Figura 2), uma vez que compreende o período de migração do inseto para a lavoura e a disseminação primária da doença (primeiras infecções). Salienta-se, no entanto, que, quanto mais cedo as plantas forem infectadas, mais cedo os sintomas dos en- 

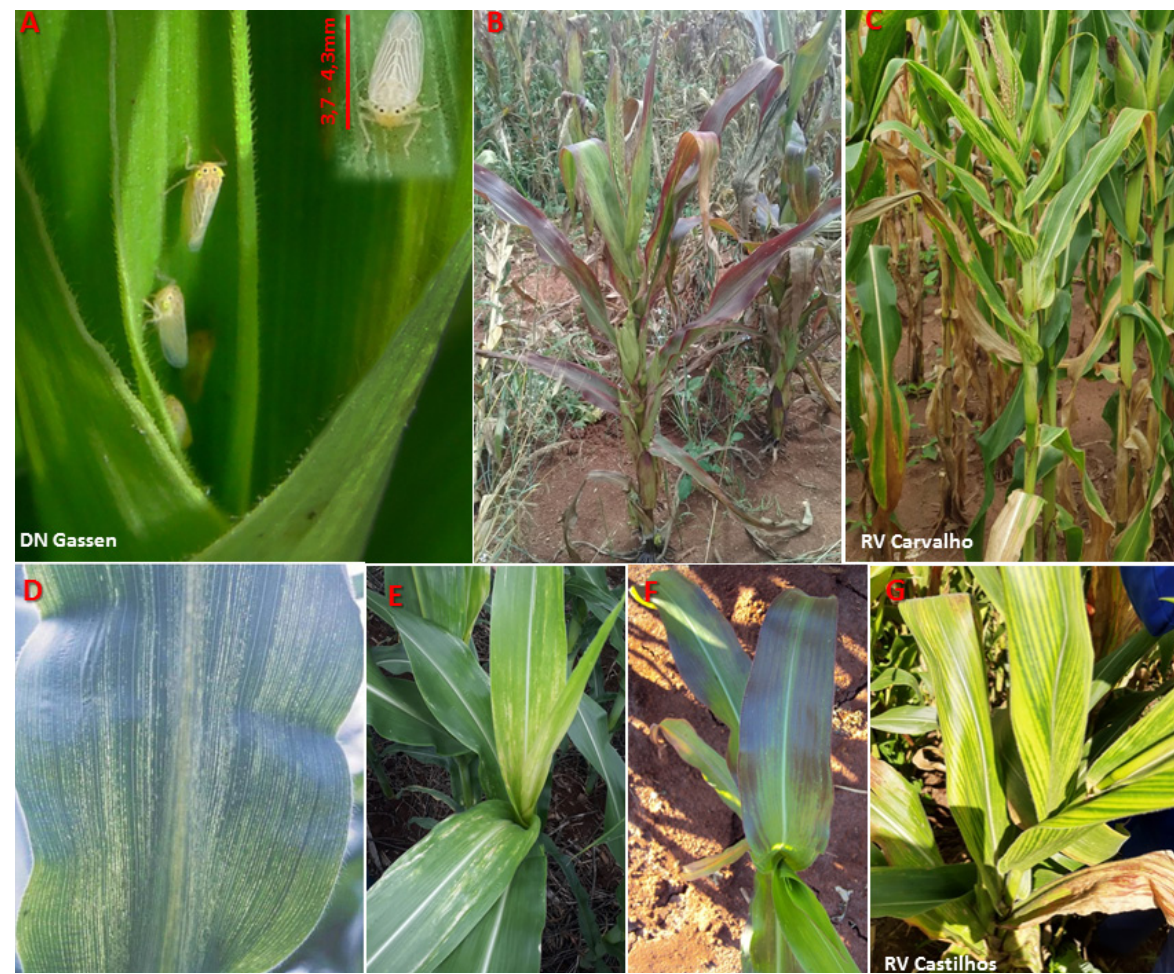

Figura 1. A) Adultos de Dalbulus maidis alojados no cartucho de uma planta de milho, com detalhe do adulto; B) planta com sintoma de enfezamento-vermelho; C) planta com sintoma de enfezamento-pálido; D) sintoma da virose-da-risca em folha de milho; E) danos de trips em milho; F) sintoma da deficiência de potássio em milho e; G) sintoma da deficiência de magnésio em milho

Fotos: DN Gassen (A, In memoriam); R.V. Carvalho (C); R.V. Castilhos (G); LP Ribeiro e MC Canale (B, D, E, F).

Figure 1. A) Dalbulus maidis adults remaining in the maize whorl, with detail of corn leafhopper adult; B) plant displaying maize bushy stunt symptom; C) plant displaying symptom of corn stunt; D) rayado-fino virus symptom in a maize leaf; E) damage of thrips in maize; F) symptom of potassium deficiency and; G) symptom of magnesium deficiency in maize plants Photos: D.N. Gassen (A, In memoriam); R.V. Carvalho (C); R.V. Castilhos (G); LP Ribeiro and $M C$ Canale $(B, D, E, F)$.

fezamentos e da virose-da-risca aparecem; contudo, tais sintomas tornam-se mais perceptíveis no período reprodutivo da cultura, especialmente dos enfezamentos causados por molicutes.

\section{Estratégias de manejo}

Apenas o controle químico do inseto-vetor na pós-emergência da cultura não tem sido suficiente para a redução dos danos ocasionados pelas doenças transmitidas pela cigarrinha-do-milho. Dessa forma, é necessário adotar outras estratégias de manejo de forma integrada e regionalizada (COTA et al., 2021), incluindo: 1) eliminação de plantas voluntárias de milho (guaxas ou tigueras) no período de entressafra; 2 ) evitar semeaduras fora do zoneamento agroclimático da cultura e cultivos sucessivos com milho na mesma área ou em áreas próximas; 3) evitar o escalonamento da semeadura de milho para reduzir a migração do inseto entre cultivos; 4) diversificar as variedades e/ou híbridos cultivados porque existem diferenças na tolerância aos patógenos (para mais informações, consultar: https://www.gov. br/agricultura/pt-br/assuntos/sanidade-animal-e-vegetal/sanidade-vegetal/ enfezamentos-do-milho) transmitidos pela cigarrinha-do-milho; 5) evitar o cultivo de outras espécies de plantas hospedeiras nas proximidades das lavouras de milho que podem servir de abrigo para sobrevivência da praga; 6) utilizar sementes tratadas com inseticidas sistêmicos [neonicotinoides (RIBEIRO et al., 2018)] para proteger as plantas nas fases iniciais de desenvolvimento, especialmente até o estágio V2.
Embora os níveis de eficácia dos produtos registrados não sejam totalmente satisfatórios, o manejo em pósemergência da cultura é imprescindível na constatação da presença da praga no período crítico da cultura (nível de controle $=$ presença do inseto vetor). Assim, recomenda-se, inicialmente, associar o manejo de cigarrinha-do-milho com aplicações direcionadas para o manejo de percevejos, com duas aplicações sequenciais de inseticidas com intervalos de 5-7 dias, iniciando na fase de "milho palito" (Figura 2). Feito isso, recomenda-se o monitoramento constante da presença e da distribuição da cigarrinha-do-milho na lavoura como subsídio para tomada de decisão quanto à necessidade de aplicações complementares. Todavia, as condições climáticas (temperatura inferior a $30^{\circ} \mathrm{C}$, umidade relativa do ar superior a $60 \%$ e ventos com velocidade entre 3 e $6,5 \mathrm{~km} / \mathrm{h}$ ), necessárias para uma boa aplicação, deverão ser criteriosamente respeitadas, buscando posicionar as aplicações ao final do dia ou à noite, momento em que as cigarrinhas apresentam menor mobilidade.

Dado o grande número de pulverizações a serem empregadas no manejo de $D$. maidis na fase inicial da cultura, recomenda-se a rotação de inseticidas com diferentes modos de ação (Figura 2), de modo a retardar a evolução de populações resistentes. Além disso, a combinação de inseticidas sintéticos com produtos biológicos à base de fungos entomopatogênicos [Isaria fumosorosea Wize (Hypocreales: Cordycipitaceae) e Beauveria bassiana (Balsamo- Crivelli) Vuillemin (Hypocreales: Clavicipitaceae)] é uma medida importante para o manejo da resistência e também aumentar a eficácia das pulverizações e incrementar o período residual. Todavia, as condições ambientais favoráveis para os fungos incitarem a doença na população (temperatura entre 26 e $27^{\circ} \mathrm{C}$, umidade relativa do ar acima de $75 \%$ e baixa radiação ultravioleta) deverão ser respeitadas.

\section{Considerações finais}

A introdução de novas pragas e a adaptação daquelas já existentes em regiões de menor favorabilidade climática ao seu desenvolvimento são uma 


\section{Cigarrinha-do-milho e percevejo - posicionamento de manejo}

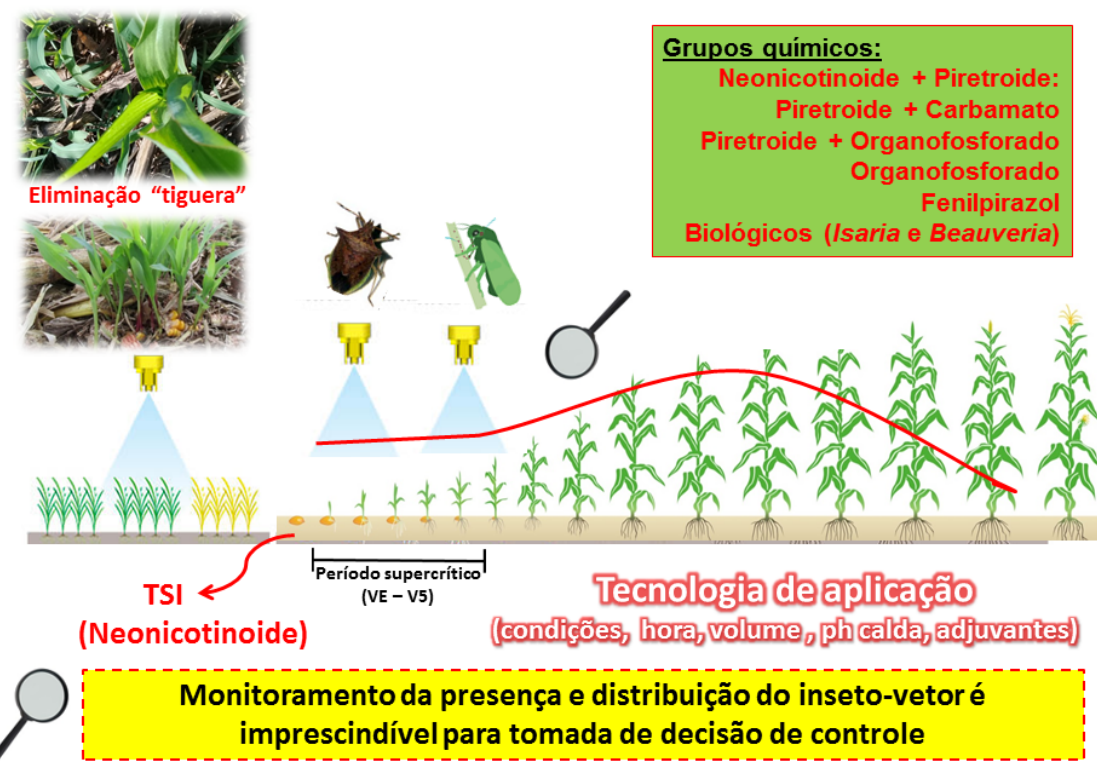

Figura 2. Esquema representativo do manejo integrado da cigarrinha-do-milho, envolvendo a eliminação de plantas voluntárias (guaxas ou tigueras), tratamento de sementes com inseticidas (TSI) e o posicionamento da aplicação de inseticidas na pós-emergência da cultura na fase supercrítica (VE-V5) para a transmissão dos patógenos dos enfezamentos, em associação com o manejo de percevejos, seguido do monitoramento da presença do inseto vetor Obs.: a linha vermelha sobre as plantas representa a dinâmica populacional da praga ao longo do ciclo da cultura.

Fonte: elaborado pelos autores.

Figure 2. Representative scheme for integrated management of corn leafhopper, including the removing of volunteer plants, seed treatment with insecticides and the positioning of insecticide application on crop post-emergency in the super-critical phase for transmission of corn stunt diseases (VE - V5), associated with management of stinkbugs, followed by monitoring of insect vector Note: the red line on the plants represents the population dynamics of the pest throughout the crop cycle.

Source: prepared by authors.

realidade cada vez mais frequente, com impacto marcante na produção e na produtividade dos sistemas agrícolas. Embora já presentes em regiões produtoras brasileiras, o impacto da cigarrinha-do-milho e das doenças do complexo de enfezamentos na cultura do milho em Santa Catarina na safra de 2020/21 foi ainda maior em virtude do desconhecimento dos agricultores em relação à identificação do problema e das principais práticas de manejo a serem implementadas. O desafio é ainda maior porque essas práticas devem ser adotadas de forma integrada em um contexto regionalizado, com a participação ativa de todos os produtores de milho. Dessa forma, ações proativas de capacitação e conscientização em relação às boas práticas agrícolas e o estabelecimento de um programa de monitoramento sistemático de $D$. maidis em nível regionalizado (Programa Monitora Milho SC), tanto na abundância de suas populações quanto na sua infectividade, são medidas imprescindíveis para mitigar o impacto da cigarrinha-do-miIho e do complexo de enfezamentos nas próximas safras no Estado.

\section{Referências}

COTA, L.V.; OLIVEIRA, I.R.; SILVA, D.D.; MENDES, S.M.; COSTA, R.V.; SOUZA, I.R.P.; SILVA, A.F. Manejo da cigarrinha e enfezamentos na cultura do milho. EMBRAPA/FAERP-PR/ SENAR-PR. Disponível em: https://sistemafaep.org.br/wp-content/uploads/2021/02/ Cartilha-cigarrinha-e-enfezamentos_WEB. pdf. Acesso em: 09 junho 2021.

GALVÃO, S.R.; SABATO, E.O.; BEDENDO, E.O. Occurrence and distribution of single or mixed infection of phytoplasma and spiroplasma causing corn stunting in Brazil.
Tropical Plant Pathology, 2020 (In press). DOI: https://doi.org/10.1007/s40858-02000381-6.

JUNQUEIRA, A.; BEDENDO, I.; PASCHOLATI, $S$. Biochemical changes in corn plants infected by the maize bushy stunt phytoplasma. Physiological and Molecular Plant Pathology, v. 65 , p. 181-185, 2004. DOI: https:// doi.org/10.1016/j.pmpp.2005.01.005.

OLIVEIRA, C.M.; FRIZZAS, M.R; OLIVEIRA, E. Overwintering plants for Dalbulus maidis (DeLong and Wolcott) (Hemiptera: Cicadellidae) adults during the maize off-season in central Brazil. International Journal of Tropical Insect Science, v. 40, p. 1105-1111, 2020. Disponível em: https://link.springer.com/article/10.1007/s42690-020-00165-0. Acesso em: 09 junho 2021.

RIBEIRO, L.P.; DEDONATTI, E.; NESI, C.N. Management of Southern corn rootworm and leafhoppers by treating seeds: field assessments in maize second crop in Southern Brazil. Maydica, v.21, e2018. Disponível em: https://journals-crea.4science.it/index.php/ maydica/article/view/1739. Acesso em: 09 de junho 2021.

TAYLOR, R.A.J.; NAULT, L.R.; STYER, W.E. EXperimental analysis of flight activity of three Dalbulus leafhoppers (Homoptera: Auchenorrhyncha) in relation to migration. Annals of the Entomological Society of America, v. 86, p. $655-667,1993$. DOI: https://doi. org/10.1093/aesa/86.5.655.

TOFFANELLI, C.M.; BEDENDO, I.P. Efeito da população infectiva de Dalbulus maidis na produção de grãos e no desenvolvimento de sintomas do enfezamento vermelho do milho. Fitopatologia Brasileira, v. 27, n. 1, p. 82-86, 2002. DOI: https://doi.org/10.1590/ S0100-41582002000100013.

VILANOVA, E.S. Efeito do estádio de desenvolvimento da planta e densidade populacional do inseto vetor, Dalbulus maidis (DeLong \& Wolcott) (Hemiptera: Cicadellidae), sobre a transmissão e danos do fitoplasma do milho. Dissertação (Mestrado), USPESALQ. 83p. 2021

WAQUIL, J.M; VIANA, P.A.; CRUZ, I.; SANTOS, J.P. Aspectos da biologia da cigarrinha-domilho, Dalbulus maidis (DeLong \& Wolcott) (Hemiptera: Cicadellidae). Anais da Sociedade Entomológica do Brasil, v. 28, n. 3, p. 413420, 1999. DOI: https://doi.org/10.1590/ S0301-80591999000300005.

WORDELL FILHO, J.A.; CHIARADIA, L.A.; RIBEIRO, L.P.; MADALÓZ, J.C.; NESI, C.N. Pragas e doenças do milho: diagnose, danos e estratégias de controle. Florianópolis: Epagri, 2016. 82p. Epagri. (Boletim Técnico, 170). 